\title{
Recovery curves of the lightning discharges occurring in the dissipation stage of thunderstorms
}

\author{
S D PAWAR* and A K KAMRA \\ Indian Institute of Tropical Meteorology, Pune, India. \\ ${ }^{*}$ Corresponding author.e-mail: pawar@tropmet.res.in
}

\begin{abstract}
Measurements of atmospheric electric field made below two thunderstorms show that all lightning discharges occurring in the dissipating stage of a thunderstorm occur at almost the same value of the predischarge electric field at the ground surface. The observation is explained on the basis of the shielding of the electric fields generated by the positive charge in the downdrafts by the negative charge in the screening layers formed around them in the subcloud layer. Our observations suggest that in the dissipating stage of the thunderstorm, the charge generating mechanisms in cloud have ceased to operate and the charge being transported from the upper to lower regions of cloud by downdrafts is the only in-cloud process affecting the surface electric field and/or enhancing the electric field stress in and below the cloud base to cause yet another lightning discharge.
\end{abstract}

\section{Introduction}

Measurements of the electric field or the lightninginduced electric field-changes, at the ground surface have been used since long time to infer the cloud charge distribution and the changes in this distribution are caused by lightning, because charges of storm itself can be sensed by measuring the electric field that they produce. Wilson (1920) measured the electric field and electric fieldchanges below thunderclouds using capillary electrometer. From these measurements, he concluded that the charge distribution inside thundercloud is of dipole nature with positive charge at the top and negative charge below it. Subsequent measurements by Schonland and Craib (1927), Wormell (1930) and Workman et al. (1942) confirmed the positive dipole structure of thunderstorm charge. From historical point of view, it is important to note that from his electric field measurements with water dropper method during 18 thunderstorms at Colaba Observatory on the west cost of India,
Banerjee (1930,1932) concluded that most of the thunderclouds were having negative charge in their front part, positive charge in the centre part and negative again in the rear part. However, several later measurements of electric field and electric field-change made at the Earth's surface reiterated the vertical positive charge structure in thunderclouds. For example, measurements of Jacobson and Krider (1976) using a network of field mills at Kennedy Space Center, Florida, USA showed that the $\mathrm{CG}$ discharges neutralize cloud charges in the range of $-10^{\circ}$ to $-40^{\circ} \mathrm{C}$ and the charges were located at the altitude of $-10^{\circ}$ to $-34^{\circ} \mathrm{C}$ temperature level. Krehbiel et al. (1979) measured the electric field changes induced by a lightning discharge at eight locations on the ground beneath a thunderstorm and estimated the location of charge sources of individual strokes of ground discharges. Brook et al. (1982) estimated the heights and magnitudes of the charges in lightning strokes to ground from simultaneous measurements of electric field changes made at seven stations covering an area of

Keywords. Recovery curves of lightning discharges; dissipation stage of thunderstorm; tropical thunderstorm; lightning. 
about $150 \mathrm{~km}^{2}$ for winter storms on the Hokuriku coast of Japan. They found that discharges lowering positive charge to the Earth often exhibited large continuing current compared to negative strokes and that the occurrence of positive strokes-to-ground is a consequence of the vertical wind shear. Analyzing the data from electric field mill network at the NASA Kennedy Space Center, Maier and Krider (1986) determined the parameters of a charge model that described the locations and magnitudes of the net changes in the cloud charge distribution that are caused by the cloudto-ground lightning. Their results for seven smallto-medium thunderstorms indicated that horizontally, locations of lightning tend to cluster in cells with an overall dimension of $5 \mathrm{~km}$ or less and that the altitudes were surprisingly constant from flash to flash and throughout the day.

The atmospheric electric field at the ground surface below a thundercloud is the summation of fields due to charges in the cloud and the space charge in the sub-cloud layer. Influence of space charge in the sub-cloud layer is well demonstrated in the observations that the coronae charge released from the elevated objects on the ground surface below thunderstorms limits the growth of the surface electric field. Therefore, the electric field above the space charge layer on the ground grows to much higher values than on the ground surface (Winn and Byerley 1975; Standler and Winn 1979; Chauzy and Raizonville 1982; Chauzy et al. 1991; Pawar and Kamra 2002). For example, measurements of Standler and Winn (1979) beneath thunderstorms with a balloon-borne electric field meter show that the magnitude of the field, a hundred meters above the ground was several times larger than that at the ground. They also observed that accumulation of charge due to coronae in the sub-cloud layer can influence the time behaviour of the electric field at the ground, the field at the ground often changes very rapidly after a lightning flash and the rate of change decreases as the field approaches the value it had prior to the flash. In contrast, the field a hundred meters above the ground increases more uniformly (linearly) during the time interval between lightning flashes. From theses observations, Standler and Winn (1979) estimated the average space charge density in horizontal layers above the Earth's surface, using Gauss's law. They found that the maximum space charge density of about $0.8 \mathrm{nCm}^{-3}$ (5000 elementary charges $\mathrm{cm}^{-3}$ ) with maximum space charge density at 30 to $50 \mathrm{~m}$ above ground level. Observations by Chauzy and Raizonville (1982) showed space charge density of about 2 to $7 \mathrm{nCm}^{-3}$ distributed over a shallow layer close to the Earth's surface.
Soula and Chauzy (1991) also observed a field of up to $65 \mathrm{kV} \mathrm{m}^{-1}$ at $603 \mathrm{~m}$ while the surface field did not exceed $5 \mathrm{kV} \mathrm{m}^{-1}$. As a consequence of the coronae space charge in the sub-cloud layer, the quasi-exponential shape of recovery curve of electric field observed at the ground after a lightning discharge changes to almost a linear one at a height of a few hundred meters above ground (Standler and Winn 1979; Soula and Chauzy 1991).

The charges distributed inside a thundercloud are the main cause of lightning. However, the charges outside thundercloud such as corona charge in the sub-cloud layer below thundercloud and screening layer at upper and lower boundaries of cloud certainly play an important role in cloud electrification; hence understanding their role in cloud electrification process is necessary. Krehbiel (1986) has emphasized that a major unresolved question in understanding the electrical behaviour of storm is concerned with the role and fate of the screening charges in the electrical budget of the storm. Positive charge in the upper portions of cloud attracts negative charge from the surrounding atmosphere. The negative ions moving from the surrounding atmosphere towards cloud are captured by cloud particles in the outer boundaries of the cloud and form screening layers around the cloud (Vonnegut 1955). These screening layers are up to tens of meters in thickness and shield the effect of the charge inside the cloud (Brown et al. 1971). The electric field observations of Vonnegut et al. (1966) made from aircraft flying over the cloud top show comparatively higher electric fields if the cloud turrets are rising. Many studies have clearly shown that screening layers form at the upper and lower boundaries of thundercloud during dissipation stage. Marshall and Lin (1992) measured the vertical profile of electric field in two thunderstorms during End-Of-Storm-Oscillation (EOSO) and found that the charge structure in the dissipation stage of thunderstorms consisted of negative charge within the cloud and positive screening charges at the upper and lower cloud boundaries; in addition, negatively charged precipitation was observed descending below the cloud base of both decaying storms. Marshall and Lin (1992) concluded that the screening mechanism operates at the upper and lower cloud boundaries to reduce electric field outside the cloud. More recently, Marshall et al. (2009) also show that screen layer do form at the upper and lower cloud boundaries during EOSO.

Here, we report our measurements of the atmospheric electric field made beneath two thunderstorms which demonstrate that in spite of the large lightning-induced field-changes the space charge in the subcloud layer contributes in maintaining the surface electric field value at an almost 
constant level in the dissipating stages of the thunderstorms.

\section{Instrumentation}

Observations have been made in Atmospheric Electricity Observatory at Pune $\left(18^{\circ} 32^{\prime} \mathrm{N}, 73^{\circ} 51^{\prime} \mathrm{E}\right.$, $589 \mathrm{~m}$ above sea level) with a field-mill described by Kamra and Pawar (2007). The field mill is installed with its sensor plates kept flush with the ground. Field-mill consists of two stators which are periodically exposed to and shielded from the atmospheric electric field with a rotor fixed on the shaft of an a.c. synchronous motor of $1400 \mathrm{rpm}$ and $12 \mathrm{~W}$ power. The diameter of rotor is $12 \mathrm{~cm}$ and it is made of non-magnetic stainless steel. The rotor is grounded using a mercury cup at the other end of the motor. Two stators are also made of the same material and of same diameter as the rotor. The stators are separated from each other by a distance of $0.5 \mathrm{~cm}$ with Teflon bushes. The stators are connected to the inverting inputs of two operational amplifiers (IC 8007). The magnitude of the charge induced on the stators is directly proportional to the intensity of the atmospheric electric field. The two amplified signals are $180^{\circ}$ out of phase with each other. These two signals, after amplification, are fed to a demodulator (IC 1456) for combination into a single wave. The reference signal for the demodulator is generated with a circular plate with sectors cut of the same shape as that of rotor and fixed at the other end of motor. This circular plate rotates through an opto-separater and generates a square wave signal of same frequency as that of input signals and exactly in phase with one of the two input signals. Neglecting charge separation on splashing, non-transient rain current, as seen by the fieldmill would depend on the plate area exposed. Since the rotor has constant angular velocity, it would result in the out-of-phase triangular voltages at the two current amplifier outputs. The differential action of the demodulator would then give the signal with zero d.c. level. It can measure electric field of $\pm 15 \mathrm{kV} \mathrm{m}^{-1}$ with response time of $0.1 \mathrm{~s}$. Normally, it can sense the lightning-induced electrostatic field-changes of an average thunderstorm 20-25 km away from the observatory. Field mill is calibrated in the laboratory by placing a flat circular plate $10 \mathrm{~cm}$ above and parallel to another similar grounded plate kept in level of the field mill sensors and raising it to different potentials. The electrical zero of field mill is checked periodically by applying ground potential to a plate place $10 \mathrm{~cm}$ above the sensors and is found to be remaining constant during the observational period. We have followed the convention that the fair-weather electric field is of negative polarity.

\section{Observations}

On November 12, 1997, a depression located at 0300 UT deep over east central Arabian Sea intensified into a deep depression and moved in northnorthwesterly direction. A trough in the easterlies existing upto $1.5 \mathrm{~km}$ above sea level extended northward from this region. Under these synoptic conditions, a thunderstorm developed at Pune at noon-time and lasted for about two hours from 1233 to 1433 LT on November 12, 1997 and produced a rainfall of $3.4 \mathrm{~cm}$. In this region, occurrence of thunderstorms is not common in this season. As shown in figure 1, the fair-weather electric field changed to foul-weather polarity (positive) and attained a maximum value of $\sim 2 \mathrm{kV} \mathrm{m}^{-1}$ during the initial period of about half an hour of the storm, but then again changed to fair-weather polarity (negative) and remained $<5 \mathrm{kV} \mathrm{m}^{-1}$ for most duration of the thunderstorm. Figure 2 shows the surface electric field record in the dissipating stage of this thunderstorm.

Out of the total of 75 lightning-induced fieldchanges produced by this storm, more than $85 \%$ are of positive polarity indicating destruction of a positive charge overhead. Pre-discharge values of the surface electric field in these field-changes vary from -5 to $+1 \mathrm{kV} \mathrm{m}^{-1}$. After each discharge, the electric field recovers back, approximately to its pre-discharge value unless the lightning frequency is so large that the field-recovery is interrupted by another discharge. However, the last three discharges of the storm exhibit field-recovery curves which are, in many respects, significantly different from the earlier ones. Different stages of field records are illustrated by $\mathrm{A}, \mathrm{B}, \mathrm{C}$ and $\mathrm{D}$ in flashes. All three discharges cause a positive field change

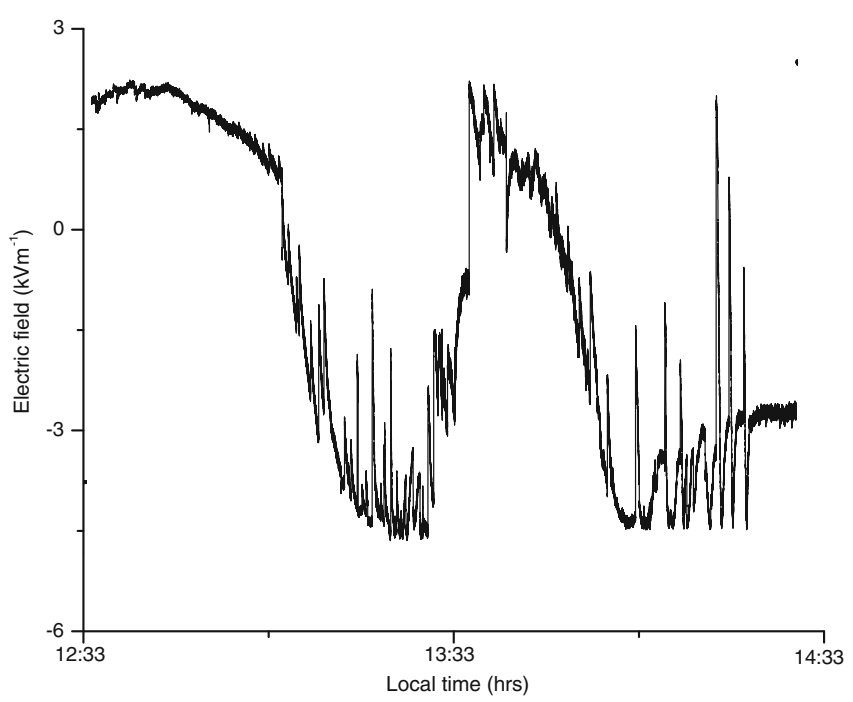

Figure 1. The surface electric field record, below thunderstorm on November 12, 1997. 


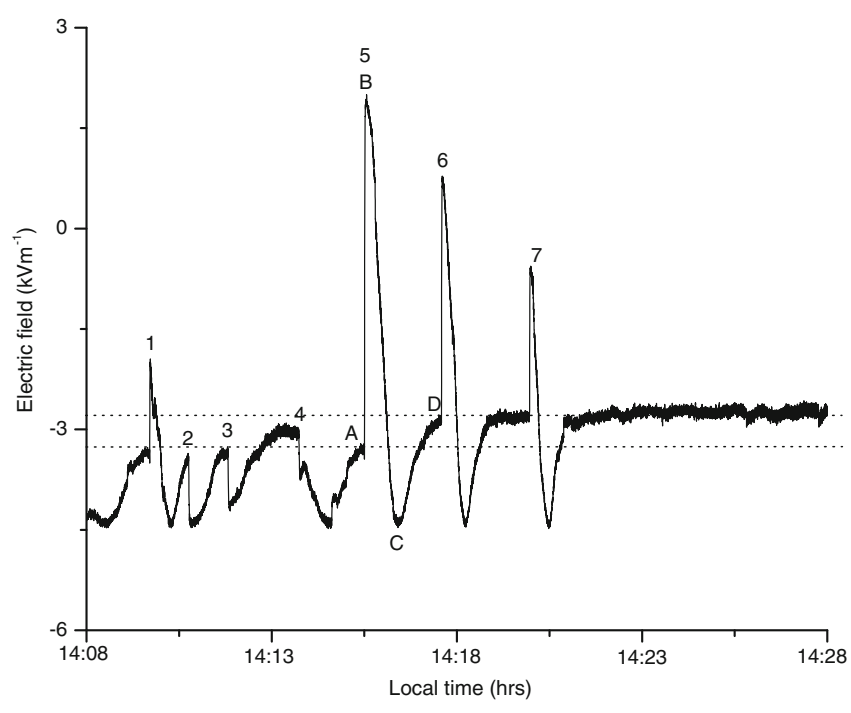

Figure 2. The surface electric field record in the dissipating stage of thunderstorm on November 12, 1997. The numbers show the flash number and A, B, C and D are the points of field reversal within the flash 5 .

(e.g., from A to B in figure 2). After each of these positive field-changes, the electric field not only recovers back from $\mathrm{B}$ to $\mathrm{C}$, almost linearly and at a much faster rate but also continues to grow to a value $C$, which has much higher negative value than its pre-discharge value at $\mathrm{A}$. Then, its magnitude starts decreasing quasi-exponentially from $\mathrm{C}$ to $\mathrm{D}$ which is approximately equal to its predischarge value. Then the next discharge occurs and the sequence repeats. As a result, all the three discharges occur when the pre-discharge electric field value is nearly the same which, as shown by pair of dotted lines in figure 2 , is between -2.95 and $-3.35 \mathrm{kV} \mathrm{m}^{-1}$ as observed here. Incidentally, the values of pre-discharge electric field, even in case of the four discharges, preceding these three discharges, are in the same range.

Almost similar sequence of the changes in recovery curves of the lightning-induced field-changes are observed in the dissipating stage of a thunderstorm that occurred on May 29, 2004 in the pre-monsoon season (figure 3 ). In this season, isolated thunderstorms develop mostly due to the instability of lower atmosphere created by the heating of the Earth's surface. In contrast to the first case, the thunderstorm of May 29, 2004, the polarity of surface electric field in dissipating stage of the storm is positive. However, similar to the first case, the lightning-induced field-changes caused by the last five discharges of the storm are of positive polarity. The electric field, after each of these positive field-changes, not only quickly recovers back from $\mathrm{B}$ to $\mathrm{C}$ but continues to drop below the predischarge value which is equal to $5.7-6.8 \mathrm{kV} \mathrm{m}^{-1}$ in this case. Then, the electric field increases ( $\mathrm{C}$ to $\mathrm{D}$ )

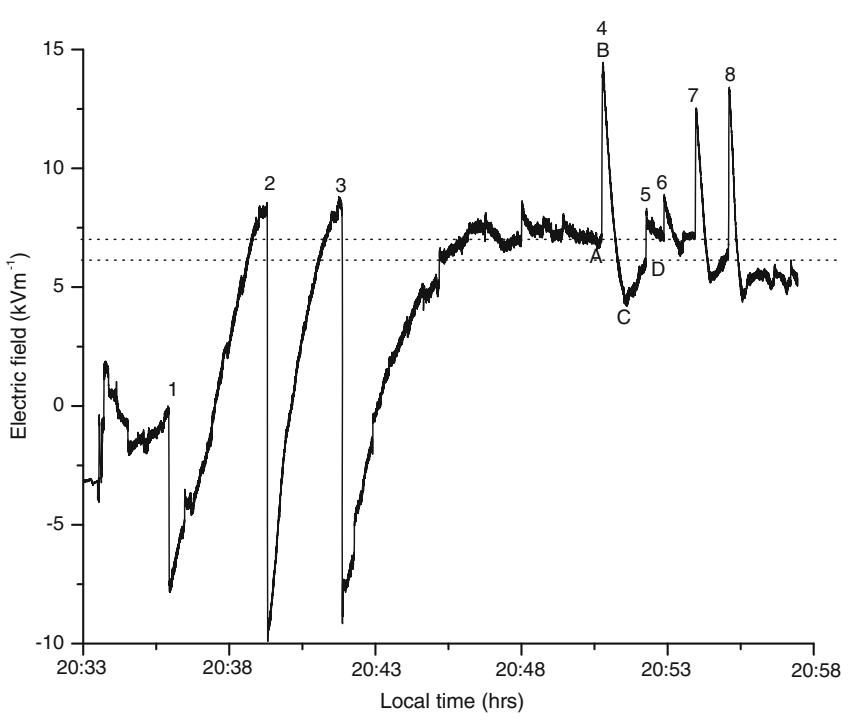

Figure 3. The surface electric field record in the dissipating stage of thunderstorm on May 29, 2004. The numbers show the flash number and A, B, C and D are the points of field reversal within the flash 4 .

to a value which is approximately equal to its predischarge value, the only exception being that of discharge number 5 in which case the field-recovery is interrupted by discharge number 6 . One important difference from the earlier case in figure 2 is that in this case, the growth of the electric field to pre-discharge value ( $\mathrm{C}$ to $\mathrm{D})$ is chaotic and not quasi-exponential.

\section{Discussion}

In the observations reported in the paper, one thunderstorm developed during an afternoon in the post-monsoon month of November and second at night in the pre-monsoon month of May. Our observations spread over 8-10 years do not show any systematic diurnal/seasonal trend in change of polarity of thunderstorms in different seasons or with the time of day. So, the polarity of charge in the sub-cloud layer and therefore the shielding produced by it does not differ from season to season, but varies from one thunderstorm to other. Any specific reason for change in polarity of thunderclouds could not be identified from our surface measurements. However, nature of the field recovery curves were almost totally determined by the polarity of charges in the cloud base and of coronae charges introduced from the ground into the sub-cloud layer.

Moore and Vonnegut (1977) suggested that the downdrafts occurring in dissipating stages of thunderstorms expose the upper positive charge of the clouds to ground and can be a cause of primary swing to negative surface electric field 
values during EOSO. However, Williams et al. (1994) attributed EOSO to the charge reversal microphysics scenario (Takahashi 1978; Saunders et al. 1991) in which the transition of positive to negative polarity of electric field is attributed to a change in the sign acquired by the precipitation particles while colliding with ice crystals. Recent observations by Pawar and Kamra (2007) and Marshall et al. (2009) support that the hypothesis of Moore and Vonnegut (1977) and show that movement of charge centers during dissipation stage of thunderstorms are responsible for the EOSO.

We interpret our observations assuming a tripole electrical structure in these thunderclouds. Last few flashes in both thunderclouds (flash numbers 5 to 7 in figure 2 and flash numbers 4 to 8 in figure 3) involve destruction of positive charge overhead and the after-discharge values of electric field recover and go beyond the pre-discharge values and then return approximately to the predischarge value before the next discharge occurs. We propose the following hypothesis to interpret these observations:

In the dissipating stage of the thunderstorm, the charge generating mechanisms in cloud have ceased to operate and, as suggested by Pawar and Kamra (2007), the charge being transported from the upper to lower regions of cloud by downdrafts, is the only in-cloud process affecting the surface electric field and/or enhancing the electric field stress in and below the cloud base to cause yet another lightning discharge. The enhancement of electrical stress in and below the cloud base in this case is not because of the generation and separation of new charge but because of bringing the two charge centers closer to each other by the downdraft in cloud.

Polarities of the electric field and field-changes in figure 2 indicate the presence of positive charge overhead. The linear field-recovery after each of the discharges 5, 6 and 7, presumably occur due to downward transport of positive charge in the downdraft and the surface electric field outgrows the pre-discharge values. As the downdraft emerges out from the cloud base and extends below in the subcloud layer, the positive charge in it attracts negative ions from the environment as proposed in the discussion of the inverted convective mechanism by Pawar and Kamra (2007). These negative ions, on reaching the downdraft outer boundary, form screening layers of the negative charge, around the downdraft. Formation of these screening layers electrically shields the effect of positive charge in the downdraft and thus starts reducing the surface electric field. As the downdraft continues to penetrate downwards in the unsaturated atmosphere, more and more water droplets in it will evaporate leaving behind the positive charge on the residues. The negative ions being attracted towards the downdraft can then travel deeper and finally to the core of the downdraft and neutralize the positive charge in it by the ion-ion recombination process. The surface electric field eventually settles down to a value caused only by the charges present inside the cloud. This value of the surface electric field is approximately the same as its pre-discharge value.

The quasi-exponential shape of recovery curves of flash numbers 1 to 3 in figure 3 which occur earlier in thundercloud, are typical of the shape during the period when the charge generating mechanisms are operating in thundercloud. These may be compared to the shape of recovery curves of flash numbers 4 to 8 in figure 3 occurring in the dissipating stage of the thunderstorm when the charge generation mechanisms have ceased to operate. Recovery curves of flashes 5 to 7 in figure 2 are similar to those of flashes 4 to 8 in figure 3 except in two aspects. Firstly, the polarity of pre-discharge ambient electric field in figure 2 is negative but positive in figure 3. Secondly, the recovery of electric field from $\mathrm{C}$ to $\mathrm{D}$ is chaotic in figure 3 rather than quasiexponential as in figure 2 which may be due to the difference in the contributions of corona charges of opposite polarities in two cases.

Even after the occurrence of the last flash in either of these two storms, the electric field does not reduce to the fair-weather value but maintains an ambient value which is almost equal to the pre-discharge value of the first flash in their dissipating stages. The observation indicates that the charges and charge distribution mainly responsible for the pre-discharge electric field for the first discharge remain almost undisturbed by the flashes occurring in the dissipating stage. Further, the charge getting neutralized in these flashes is brought from the regions where its effect on the surface electric field in its pre-discharge position is negligible.

In our proposed hypothesis, it is the positive charge brought down with the downdraft which is getting destroyed in these flashes occurring in dissipating stage of the storm. The proposal thus supports the observation that most of the CG discharges occurring in the dissipating stage of the storms, transfer positive charge to the ground (Pierce 1955; Fuquay 1982; Orville et al. 1983).

Theoretical model results of Mansell et al. (2002) require that the presence of the LPCC is essential to trigger a $C G$ discharge. In our hypothesis of the inverted convective mechanism, the negative charge accumulating around the downdraft may serve the role of the LPCC in triggering the discharge. 


\section{Conclusions}

Our observations show that the lightning discharges occurring in the dissipation stage of thunderstorm occur at nearly the same value of the surface electric field. Shape of recovery curves of the discharges can be explained by the formation of screening layer of negative charge around the positive charge being transported down by the downdrafts in the sub-cloud layer. Observations suggest that positive charge being transported by downdrafts is the dominant in-cloud process in the dissipation stage of thunderstorm affecting the surface field and/or enhancing the electric field stress in and below the cloud base to cause yet another discharge.

\section{Acknowledgement}

One of the authors (AKK) acknowledges the support under INSA Senior Scientist Program.

\section{References}

Banerjee S K 1930 The electric field of overhead thunderclouds; Quart. J. Roy. Meteorol. Soc. 56305.

Banerjee S K 1932 The electric field of overhead thunderstorms; Phil. Trans. Roy. Soc. London, Ser. A 231 1-27.

Brook M, Nakano M, Krehbiel P and Takeuti T 1982 The electrical structure of the Hokuriku winter thunderstorms; J. Geophys. Res. 87 1207-1215.

Brown K A, Krehbeil P R, Moore C B and Sargent G N 1971 Electrical screening layers around charged clouds; J. Geophys. Res. 76 2825-2835.

Chauzy S and Raizonville P 1982 Space charge layer created by corona at ground level below thunderclouds: Measurements and modeling; J. Geophys. Res. 87 3143-3148.

Chauzy S, Medale J C, Prieur S and Soula S 1991 Multilevel measurements of electric field underneath of a thundercloud, 1. A new system and associated data processing; J. Geophys. Res. 96 22,319-22,326.

Fuquay D M 1982 Positive cloud-to-ground lightning in summer thunderstorms; J. Geophys. Res. 87 7131-7140.

Jacobson E A and Krider E P 1976 Electrostatic field changes produced by Florida lightning; J. Atmos. Sci. 33 103-117.

Kamra A K and Pawar S D 2007 Evolution of lighting in an isolated hailstrom of moderate size in the tropics; $J$. Geophys. Res. 112 D20205, doi: 10.1029/2006JD007820.

Krehbiel P R, Brook M and McCrory R A 1979 An analysis of the charge structure of lighting discharges to ground; J. Geophys. Res. $842432-2456$.

Krehbiel P R 1986 The electrical structure of thunderstorms; In: The Earth's Electrical Environment (Washington DC: National Academy Press), pp. 90-113.

Mansell E R, MacGorman D R, Ziegler C L and Straka J M 2002 Simulated three-dimensional branched lightning in a numerical thunderstorm model; J. Geophys. Res. 107, doi: 10.1029/2000JD000244.

Marshall T C and Lin B 1992 Electricity in dying thunderstorms; J. Geophys. Res. 979913.

Marshall T C, Stolzenburg M, Krehbiel P R, Lund N R and Maggio C R 2009 Electrical evolution during the decay stage of New Mexico thunderstorms; J. Geophys. Res. 114 D02209, doi: 10.1029/2008JD010637.

Maier L M and Krider E P 1986 The charges that are deposited by cloud-to-ground lightning in Florida; J. Geophys. Res. 91 13,275-13,289.

Moore C B and Vonnegut B 1977 The thundercloud in Lightning; (ed.) R H Golde (San Diego, California: Academic) $151-98$

Orville R E, Henderson R W and Bosart L F 1983 An East cust lightning detection network; Bull. Am. Meteor. Soc. 64 1029-1037.

Pawar S D and Kamra A K 2002 Recovery curves of the surface electric field after lightning discharges occurring between the positive charge pocket and negative charge centre in a thundercloud; Geophys. Res. Lett. 29 2108-2111.

Pawar S D and Kamra A K 2007 The end-of-stormoscillation in tropical air-mass thunderstorms; J. Geophys. Res. 112 D03204, doi: 10.1029/2005JD006997.

Pierce E T 1955 The development of lightning discharges; Quart. J. Roy. Meteorol. Soc. 81 229-239.

Saunders C P R, Keith W D and Mitzeva R P 1991 The effect of liquid water on thunderstorm charging; J. Geophys. Res. 96 11,007-11,017.

Schonland B F J and Craib J 1927 The electric field of South African thunderstorms; Proc. Roy. Soc. London, Ser. A $114229-243$.

Soula S and Chauzy S 1991 Multilevel measurement of the electric field underneath a thundercloud. 2. Dynamical evolution of ground space charge; J. Geophys. Res. 96 $22,327-22,336$.

Standler R B and Winn W P 1979 Effects of coronae on electric field beneath thunderstorms; Quart. J. Roy. Meteorol. Soc. 105 285-302.

Takahashi T 1978 Riming electrification as a charge generation mechanism in thunderstorms; J. Atmos. Sci. 35 $1536-1548$.

Vonnegut B 1955 Proceedings 'International Conference on Atmospheric Electricity', Geophys. Res. Pap. No. 42, Air Force Cambridge Research Centre, Bedford, Mass, p. 169.

Vonnegut B, Moore C B, Espinola R P and Blau Jr H H 1966 Electrical potential gradients above thunderstorms; J. Atmos. Sci. 23 764-770.

Wilson C R T 1920 Investigations on lightning discharges and on the electric field of thunderstorms; Phil. Trans. A $22173-115$.

Williams E R, Zhang R and Rydock R 1994 Mixed phase microphysics and cloud electrification; J. Atmos. Sci. 48 2195.

Winn W P and Byerley L G 1975 Electric field growth in thunderclouds; Quart. J. Roy. Meteorol. Soc. 101 979-994.

Workman E J, Holzer and Pelsor G T 1942 The electrical structure of thunderstorms; NACA Tech. Note $\mathbf{8 6 4}$ $1-47$.

Wormell T W 1930 Vertical electric currents below thunderstorms and showers; Proc. Roy. Soc. London, Ser. A 127 $567-590$. 